\title{
Enhancing Undergraduate Student Success in STEM Fields through Growth-Mindset and Grit
}

\author{
Gokhan Hacisalihoglu ${ }^{1, *}$ (D) , Desmond Stephens ${ }^{2}$, Sonya Stephens ${ }^{2}$, Lewis Johnson ${ }^{3}$ and \\ Maurice Edington 4 \\ 1 Department of Biological Sciences, Florida A\&M University, Tallahassee, FL 32307, USA \\ 2 Department of Mathematics, Florida A\&M University, Tallahassee, FL 32307, USA; \\ desmond.stephens@famu.edu (D.S.); sonya.stephens@famu.edu (S.S.) \\ 3 Department of Physics, Florida A\&M University, Tallahassee, FL 32307, USA; lewis.johnson@famu.edu \\ 4 Department of Chemistry, Florida A\&M University, Tallahassee, FL 32307, USA; \\ maurice.edington@famu.edu \\ * Correspondence: gokhan.h@famu.edu
}

Received: 15 September 2020; Accepted: 6 October 2020; Published: 12 October 2020

\begin{abstract}
Concern about graduation rates in higher education has led universities to offer courses that help students develop success skills. Scientist Life Skills, a new course for freshman at Florida A\&M University, focuses on helping students matriculate into majors via development of growth mindset, grit, and critical thinking. Here, we assessed the outcomes of this course and explored the associations between building life skills and student success. A series of mindset, grit, and critical-thinking assessment measures were used to collect data before and after the course. Our results showed that the new course achieved its intended goals of providing STEM students with a set of tools that help them seamlessly transition into the university and successfully matriculate through their majors. Specifically, the course design significantly moved students toward a growth-mindset, increased their critical thinking, and their second-semester grade point averages (GPAs). This model life skills course can be adopted in non-STEM areas as well.
\end{abstract}

Keywords: college success; higher ed; professional skills; first-year; STEM education; growth mindset

\section{Introduction}

Improving graduation rates, particularly in science, technology, engineering, and mathematics (STEM) disciplines, is increasingly important nationwide. It is predicted that there will be a shortage of over two million STEM workers by the year 2025, highlighting the urgent need for STEM graduates to maintain U.S. economic competitiveness [1]. Over the past several years, there has been growing focus on college success courses to help students develop life skills such as growth mindset, grit, critical thinking, and the ability to work collaboratively.

Achieving one's potential often starts with seeing opportunities and meeting challenges by focusing on the positive; these habits of mind are known as growth mindset [2]. Growth mindset refers to the students' belief in improving their own academic success with a combination of effective study strategies and effort. Importantly, the level of one's mindset can be measured using a 0 to 60 mindset scale developed by Dweck [3]. Additionally, Blackwell et al. [4] showed that the motivational framework of growth mindset helped increase student performance in mathematics. In another study, Yeager and Dweck [5] showed that growth mindset strategies were beneficial to students who faced adversity while navigating their educational programs. Yeager et al. [6] also concluded that online growth mindset intervention not only improved mathematics course enrollment but also the grades of low-achieving learners. 
Grit, the ability to keep getting up after falling, can be described as a passion for long-term goals and the self-control to achieve them [7]. In a 2009 study, Duckworth and Quinn reported that higher grit scores (on a 0 to 5 grit scale) can be equated with higher academic and personal achievement [8]. While Duckworth et al. [9] reported that grit is not always the most important forecaster of long-term achievement, it has been shown to help increase 4-year graduation rates. Additionally, Kelly et al. [10] found that grit was an important contributor to the success of cadets at West Point Military Academy. Moreover, Lucas et al. [11] showed that gritty students who were persistent in their academics, later showed similar grittiness after being employed.

Over the past decade, Duckworth's research has drawn increased attention to grit [7-9]. More recently, however, there is a lack of consensus in the literature whether academic success can be influenced by grit [12]. While the advocates of grit have argued that being gritty is a key trait of successful individuals, there is some concern over its limitations, ability, testing, and teachability. For example, it was reported by Crede et al. [13] that the impact of grit was low on academic success and moderately correlated with performance in a study of online articles with the keyword grit. Moreover, Crede [14] further suggested that there may be possible alternative predictors of performance in determining success other than grit. A research study conducted by Muenks et al. [15] concluded that only perseverance component of grit is a significant predictor of final grades, while passion is not. Moreover, Muenks et al. suggested alternative predictors such as self-efficacy [15].

The rapidly changing world brings new challenges where critical thinking is needed more than ever. Critical thinking can be defined as a higher-order thinking skill for in-depth evaluation, identifying linkages, and solving problems creatively [16]. A 0 to 40 scale Critical-thinking Assessment Test (CAT) was developed to evaluate students' critical-thinking skills at Tennessee Tech University [17].

Research has increasingly shown that life skills such as growth mindset and self-efficacy are closely associated with academic performance and therefore could be used for early identification of struggling students and to flag students who might need academic support [18]. In an effort to enhance the overall quality of the STEM educational experience at Florida Agricultural and Mechanical University (FAMU), the College of Science and Technology developed a new course for first-year STEM majors titled "ISC 1058: Scientist Life Skills". The goal of this course was to introduce students to success strategies such as growth mindset, grit, and critical thinking. The additional student learning outcomes were problem solving, handling failure, metacognition, goal setting, and time management. The current study has focused on the three skills (growth mindset, grit, and critical thinking) because of their published scales availability. While growth mindset and grit skills have shown to positively impact learners' academic performance, so far no research has been reported on undergraduate student success among STEM majors. Therefore, there is a research gap in this subject.

The research hypothesis: Students gaining scientist life skills via the new ISC1058 course will have moved to a more growth mindset, increased their grit, improved their critical thinking, and shown higher levels of academic success.

The objectives of this study are: (1) describe the experience of a first-year STEM success course and the intersection with growth mindset, grit, and critical thinking; (2) determine the impact of the ISC1058 Scientist Life Skills course on students' mindset, grit, and CAT scores; and (3) evaluate the relationship of growth mindset, grit, and critical thinking with academic performance and grade point average (GPA).

\section{Materials and Methods}

\subsection{Course Structure and Assessment}

The current study was conducted with a cohort of first-year students at Florida A\&M University (FAMU) who enrolled in the College of Science and Technology's Scientist Life Skills course during the Fall 2019 semester (Table S1). FAMU is a midsize, public, historically black university (HBCU) located in Tallahassee, Florida, U.S.A. Table 1 summarizes the characteristics of participants in this 
study. The two textbooks used were Mindset: The new psychology of success (Dweck, 2006) and Grit: the power of passion and perseverance (Duckworth, 2016). The course included educational videos and professional workshops on growth mindset, grit, and critical thinking. Students attended two weekly classes, totaling $150 \mathrm{~min}$, that included activities in which students worked on case studies, essays, and a final project. The final grade was based on assignments (reading and writing), in-class activities, a midterm exam, quizzes, and a final project that culminated in student group presentations (Supplemental Table S1). Table 2 summarizes the Scientist Life Skills (ISC1058) course examined in the current study. A generalized list of major topics includes grit, growth mindset, and critical thinking can be found in Figure 1 .

Table 1. Summary of Demographics of Students Who Attended ISC1058.

\begin{tabular}{cc}
\hline Gender & \\
\hline Female & $72 \%$ \\
Male & $28 \%$ \\
\hline Major & \\
\hline Bio-PreMed & $52 \%$ \\
Information Technology & $20 \%$ \\
Biology & $12 \%$ \\
Computer Science & $12 \%$ \\
Computer Engineering & $4 \%$ \\
\hline Ethnicity/Race & \\
\hline African American & $95 \%$ \\
White & $4 \%$ \\
Other race & $5 \%$ \\
\hline Other Student Attributes & \\
\hline First-generation college student & $28 \%$ \\
\hline Taken AP science courses in high school &
\end{tabular}

Table 2. Comparative Pre- and Post-Cat Scores From 2014 to 2018 (Control) and 2019 (Experimental) Cohorts at FAMU. the Control Group Was Subjected to Standard Major Curriculum Courses While the Experimental Group Was Subjected to Standard Major Curriculum Courses and isc1058 Course (Scientist Life Skills). Pre-Cat and Post-Cat Means Were Not Significantly Different $(p=0.0072)$. Cat, Critical-Thinking Assessment Test.

\begin{tabular}{cccccccccc}
\hline & \multicolumn{3}{c}{ PRE-CAT } & \multicolumn{3}{c}{ POST-CAT } \\
\hline & $\boldsymbol{n}$ & Min. & Max. & Mean & SD & Min. & Max. & Mean & SD \\
\hline & \multicolumn{4}{c}{ Cohort } & \multicolumn{3}{c}{ Control Cohorts } \\
\hline Fall 2014-All STEM & 53 & 3 & 21 & 12.19 & 4.51 & 2 & 21 & 11.3 & 4.57 \\
Spring 2015-Biology & 81 & 2 & 22 & 11.3 & 4.51 & 2 & 29 & 11.53 & 5.28 \\
Fall 2016-SCALEUP & 108 & 4 & 22 & 11.77 & 3.98 & 2 & 25 & 11.4 & 4.41 \\
Fall 2016-Biology & 43 & 3 & 29 & 13 & 6.1 & 3 & 26 & 13.77 & 6.45 \\
Fall 2016-BSC1010-8 & 15 & 5 & 21 & 11.2 & 4.57 & 2 & 19 & 10.36 & 5.03 \\
Fall 2016-BSC1010-9 & 15 & 7 & 18 & 12.93 & 3.65 & 8 & 18 & 13 & 3.55 \\
Fall 2016-BSC1010-10 & 15 & 6 & 17 & 10.27 & 3.17 & 4 & 17 & 10.13 & 4.31 \\
Fall 2016-BSC1010-3 & 15 & 6 & 18 & 12 & 3.4 & 6 & 19 & 11.78 & 3.51 \\
Fall 2016-BSC1010-7 & 15 & 4 & 21 & 11.53 & 5.17 & 3 & 20 & 11 & 4.87 \\
Fall 2018-All STEM & 66 & 5 & 30 & 13.65 & 4.79 & 5 & 26 & 12.48 & 4.49 \\
\hline & \multicolumn{3}{c}{ Experimental Cohort } & & & & \\
\hline Fall 2019-All STEM & 79 & 5 & 22 & 12.78 & 3.67 & 2 & 25 & 12.89 & 4.39 \\
TOTAL & 505 & 4.55 & 21.91 & 12.06 & 0.98 & 3.55 & 22.27 & 11.79 & 1.14 \\
\hline
\end{tabular}




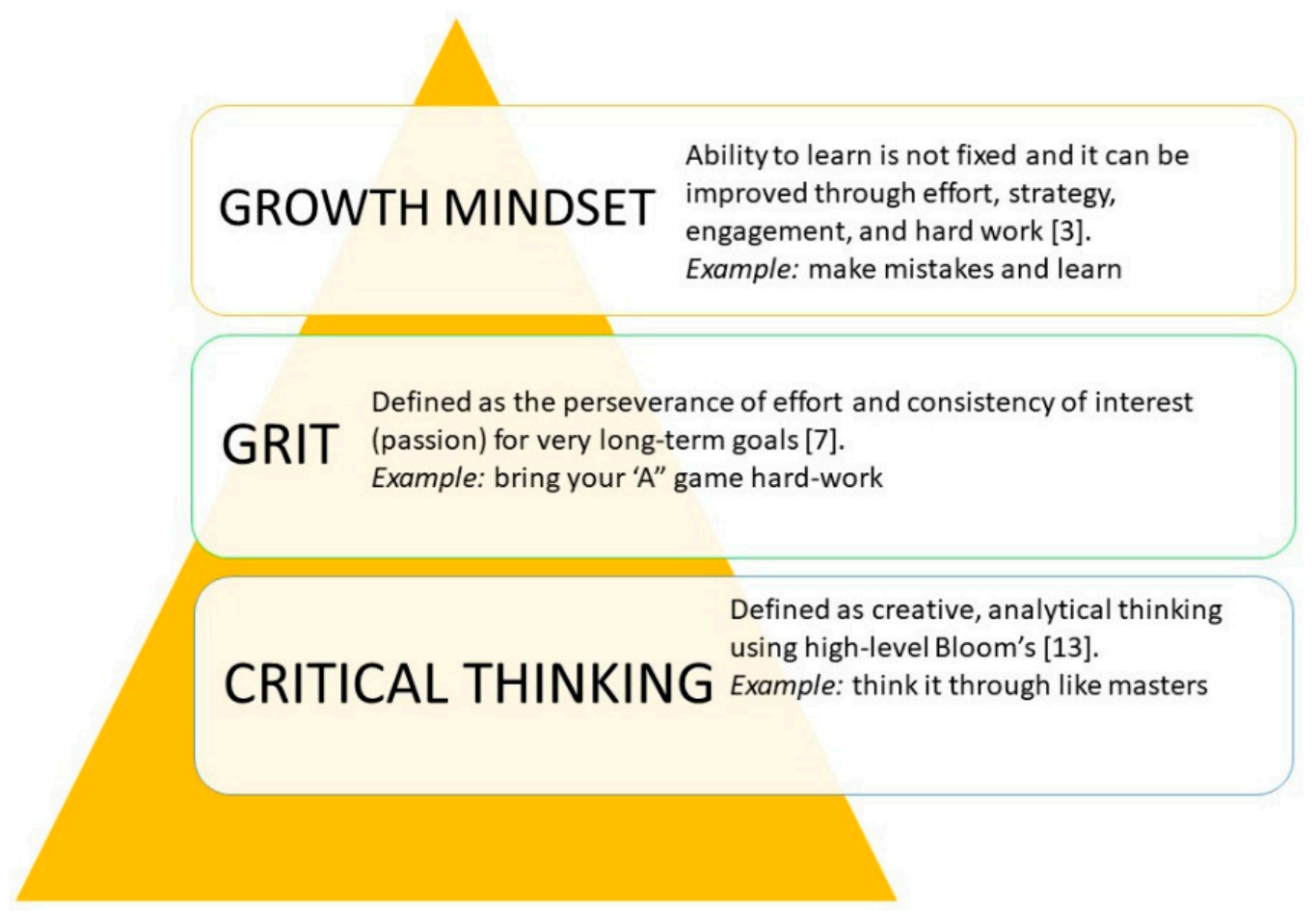

Figure 1. Overall Representation of isc1058: Scientist Life Skills Topics for Academic Success.

An online survey was conducted at the end of the semester to assess student perceptions of Scientist Life Skills (ISC1058) course. The open-response items were adapted from departmental surveys and reviewed for content validity by researchers with expertise in STEM teaching and assessment. The open-ended responses were read and grouped into major theme categories. All students were majors in STEM subjects including Biology, Pre-Medicine, Computer Science, or Information Technology. Of the students enrolled in the course, $72 \%$ were female and 95\% were African American (Table 1). Furthermore, the pre-survey revealed that $24 \%$ of students had taken an advanced placement (AP) science course at their high school. The pre-survey also revealed that $28 \%$ of the students were first-generation college students (Table 1).

\subsection{Measurements of Growth Mindset, Grit, and Critical Thinking}

Life skills of growth mindset, grit, and critical thinking are described and summarized in Figure 1. To assess students' growth-mindset, grit, and critical-thinking skills before and after the course, the Mindset, Grit, and CAT instruments were administered in the second and thirteenth week of the semester. Students' pre- and post-course growth mindset was assessed with the mindset quiz adapted from Diehl [19], Kannangara et al. [20], Babic et al. [21], and Kannangara et al. [22]. The mindset quiz is fully available online at "http://www.classroom20.com/forum/topics/motivating-students-with". The mindset is a 20-item questionnaire assessing items associated with mindset. Participants indicated their agreement with each item on a scale of 0 to 60 , where higher scores represented a stronger growth mindset and lower scores were associated with a more fixed mindset. More specifically, there were four sub-scales: strong growth mindset (45-60 points), growth mindset with some fixed ideas (34-44 points), fixed mindset with some growth ideas (21-33 points), and strong fixed mindset (0-20 points) [3,19]. Grit was assessed with the established grit scale [7]. The Grit test is a 12-question, multiple-choice quiz in which participants indicate their agreement with each statement on a scale of 1 to 5 . The maximum score on this scale is 5 (extremely gritty), and the lowest score on this scale is 1 (not at all gritty).

Students' pre- and post-course critical thinking was assessed using Tennessee Tech University's Critical-thinking Assessment Test (CAT) which consists of 15 open-ended questions. The CAT is a well-established test that is the product of extensive development and refinement at several 
universities nationwide. The CAT, developed as a 1-h test with short-answer essay questions, measures critical thinking and real-world problem-solving skills [17].

The CAT study participants were freshman STEM students at FAMU over five semesters: Fall 2014, Spring 2015, Fall 2016, Fall 2018 (control cohorts), and Fall 2019 (experimental cohort) (Table 2). The experimental cohort took the ISC1058 course.

Four semesters of various cohorts (General Biology I sections, all STEM sections, all biology sections) were located in control group. The control group was subjected to standard major curriculum courses while the experimental group subjected to standard major curriculum courses and ISC1058 course (Scientist Life Skills). Therefore, Fall 2019 with all STEM sections automatically served as experimental group under the current study (Table 2).

Overall course (ISC1058) end of the semester (Fall 2019) academic rankings were assessed as follow: The upper group were those with the highest grades; and the lower group were those with the lowest grades (Table 3).

Table 3. Comparing CAT, GRIT, and Mindset Scores to Course End of the Semester Academic Rankings Based on Their Course Grades.

\begin{tabular}{cc}
\hline & (a) Upper Group: Highest Academic Rank \\
\hline Student & Notes \\
Student 1 & highest CAT improvement \\
Student 2 & high MINDSET improvement \\
Student 3 & highest post-MINDSET, high CAT improvement \\
Student 4 & high CAT improvement \\
\hline & (b) Lower Group: Lowest Academic Rank \\
\hline Student & Notes \\
Student 22 & lowest pre-CAT \\
Student 23 & low pre-CAT \\
\hline
\end{tabular}

\subsection{Ethics Statement}

The Institutional Review Board at Florida Agricultural and Mechanical University has approved the work described in this study under the "FAMU IRB Approval Number 1302612-4". The participants were asked to complete surveys pertaining to the Scientist Life Skills course content. The requests and the surveys were conducted by the FAMU internal evaluator. For each assessment and survey including mindset quizzes, grit scale assessments, and CAT administrations, participants were informed of the purpose, how the data might be used, and the anonymity of the results through a detailed e-mail letter. The completion of surveys and assessments was taken as voluntary consent to participate. The FAMU-IRB did not require a signature on the consent form for these assessments as there was no risk associated with any of the data collected to individuals participating. The act of participants completing and submitting the surveys and assessments was considered implied consent to participate. All data were analyzed anonymously.

\subsection{Data Analysis}

Data were analyzed in SigmaPlot (Systat Software, San Jose, CA, USA) and Microsoft Excel. The quantitative variables were examined using means and standard errors (SE). Changes in variables (pre- and post-course) were examined using Student's $t$-test. The correlation coefficients were calculated using SigmaPlot (Systat Software, San Jose, CA, USA). 


\section{Results}

\subsection{Pre- and Post-Course Testing of Mindset, Grit, and Critical Thinking}

Overall, the ISC1058 course led to improvements in all test scores (Figure 2). Student post-course growth-mindset scores were significantly (15\%) higher than pre-course scores (Figure 2A). Student grit scores increased 5.3\% post-course compared with pre-course (Figure 2B). Student post-course CAT scores were $8 \%$ higher than the pre-course scores, although this difference was not statistically significant (Table 2). Similarly, the average pre- and post-course CAT scores for the past 10 semesters of non-ISC courses were also not significantly different (Table 2).
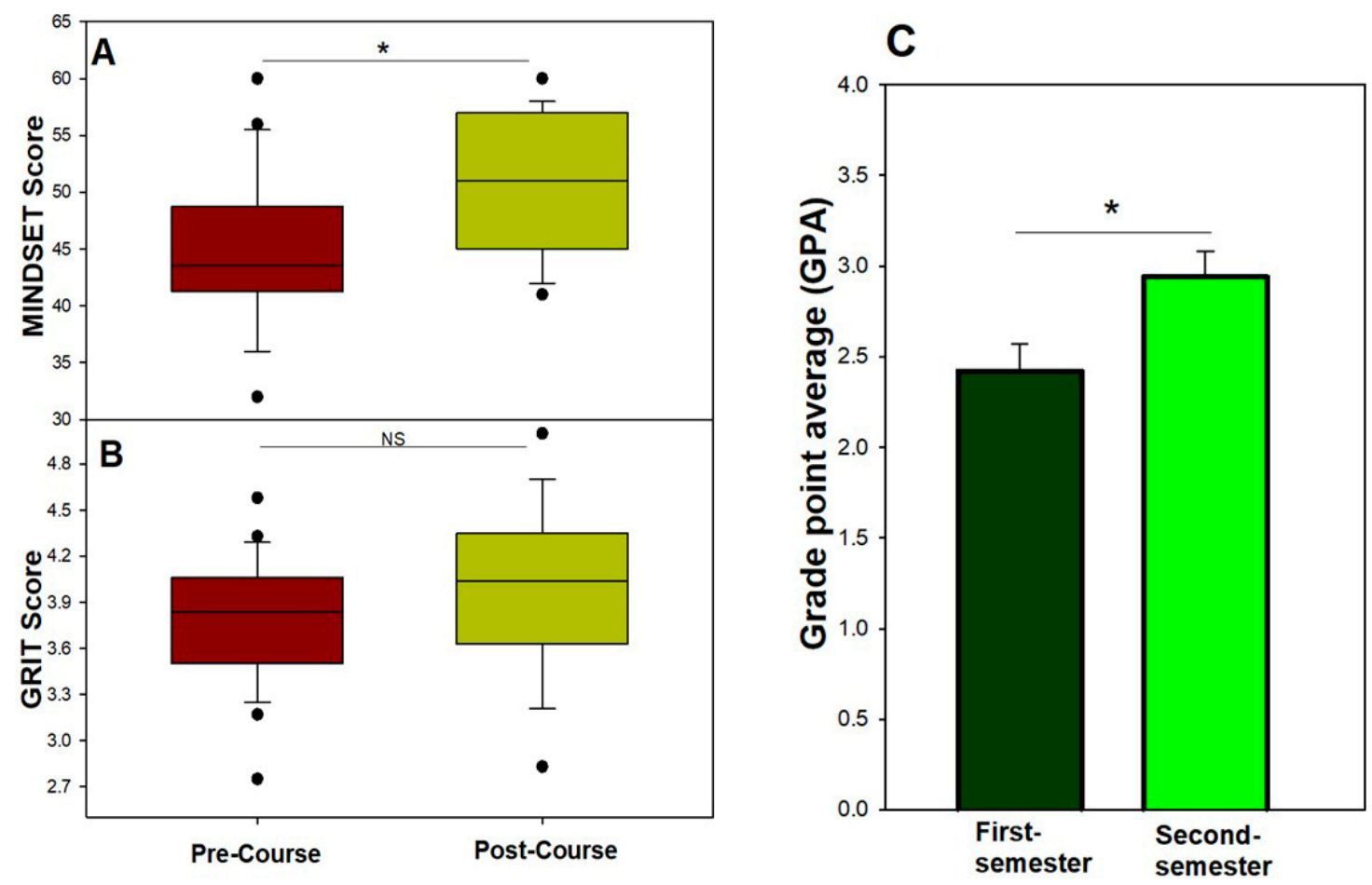

Figure 2. Comparison of Pre- and Post-Course Tests. (A) Mindset; And (B) GRIT. (C) First- and Second-Semester Grade Point Averages (GPA) of isc1058 Students. Means Were Significantly Different (Student's T-Test, $\left.{ }^{*} p<0.05\right)$ for (A) and (C) but Not Significantly Different for (B).

\subsection{First-Semester and Second Semester GPA}

Students who took the ISC1058 course had significantly higher GPAs not only in the first semester (76\% finished averaging a " $\mathrm{C}$ " or better) but also in the second semester $(100 \%$ earned " $\mathrm{C}$ " averages or better) (Figure 2C).

\subsection{Relationship between Student Grit, Growth Mindset, and Critical Thinking Elements}

Overall, average post-course life skill scores exhibited positive relationships with the first-semester GPA (Figure 3). Post-course grit exhibited a stronger correlation with the first-semester GPA compared with the other two skills $(r=0.43$, Figure $3 \mathrm{~A})$. There was also a moderate positive correlation between post-course growth mindset and first-semester GPA $(r=0.38$, Figure 3B) and post-course CAT $(r=0.34$, Figure 3C). 

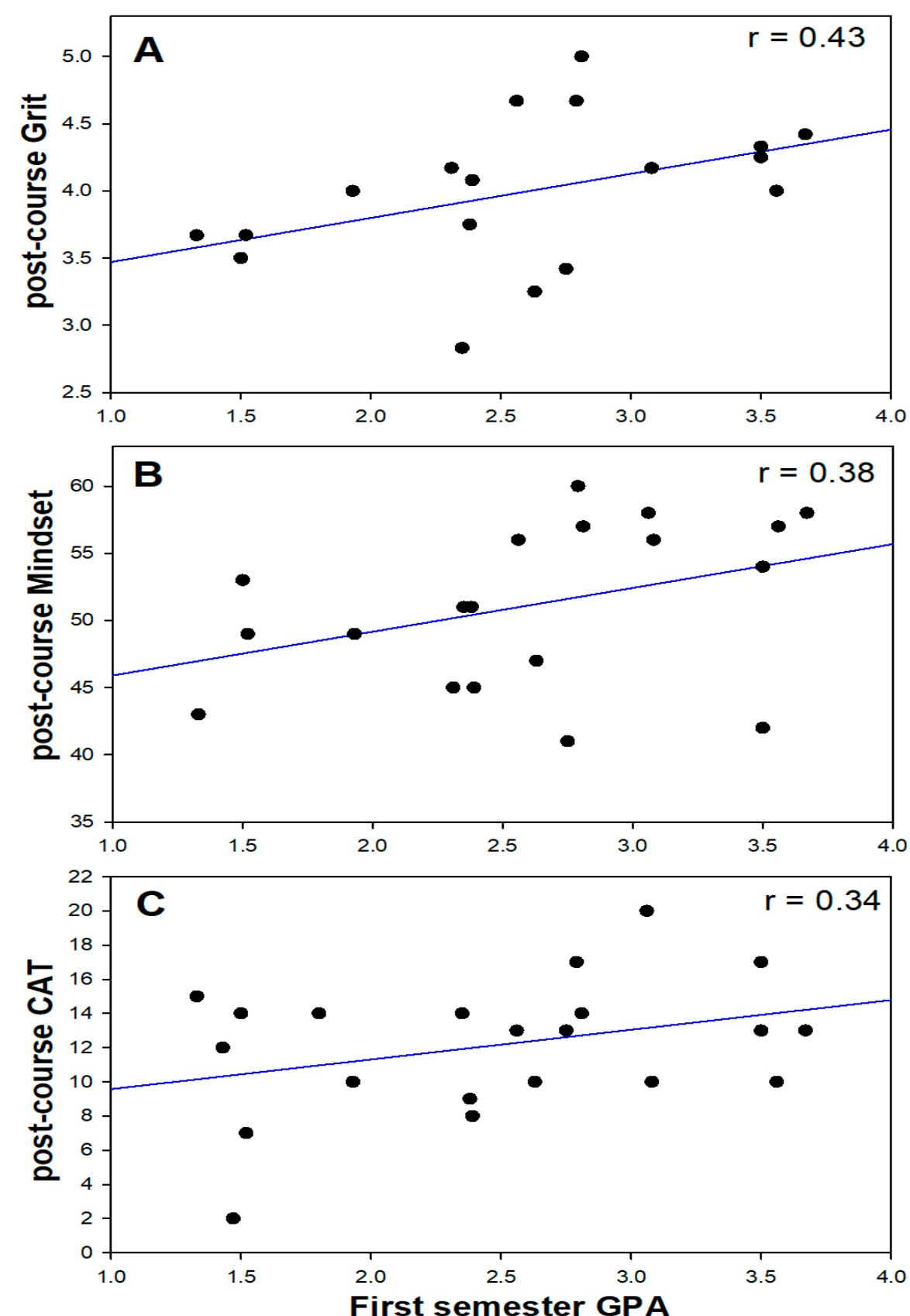

Figure 3. Correlations Between First-Semester GPA and (A) Post-Course Grit; (B) Post-Course Mindset;

(C) Post-Course CAT. $\mathrm{r}=$ Pearson's Correlation Coefficient.

\subsection{Academic Rank Outcomes}

The results from the current study is summarized in two groupings in Table 3. The group with the highest academic rank in the ISC1058 class also had the highest scores for the life skills, including being in the highest or the high CAT improvement groups (Table 3a). Notably, the group with the lowest academic rank in the ISC1058 class also had the lowest pre-course CAT scores (Table 3b).

\subsection{Student Reactions to the ISC1058 Course}

Students who took ISC1058 were surveyed to determine their perceptions of the course and other relevant information about their first semester (Table 4). Student responses indicated that the ISC1058 course was helpful as a first-year STEM success course. As indicated by the responses in Table 4, 
students were able to learn about growth mindset, grit, and higher-order critical-thinking skills during the ISC1058 course.

Table 4. Survey Results for the Perceptions of Students Enrolled in ISC1058.

(a) Perceptions of Students Enrolled in ISC1058 Scientist Life Skills
ISC1058 greatly enhanced my GRIT and MINDSET
As a result of taking this course, I am more aware of critical thinking, metacognition, grit, and growth
mindset.
I am willing to make more positive study decisions (metacognition).
I am more willing to put more effort, keep trying, visit during office hours, and be inspired by success.
I learned something new, new ideas and strategies to improve my success, and my confidence in STEM
increased.
I learned Blooms taxonomy from remembering to creating higher-order deeper learning levels.
I recommend this class for the students in the future.
(b) What Aspects of This Course Did You Like Most?
The study habits I created
In-class activities helped better understand the material
Awesome class
My instructor was very good
The class was very engaging and helpful

\section{Discussion}

Scientist Life Skills (ISC1058) is a college success course specifically designed for first-year STEM majors at FAMU. The university is located in the southeastern United States and has an undergraduate population of approximately 10,000 students, $90 \%$ of whom are African American. FAMU has become a leader in the implementation of pedagogical best practices for improving STEM instruction and inspiring underrepresented students to pursue degrees in STEM fields [23,24].

Scientist Life Skills (ISC1058) is a new required course developed by the College of Science and Technology at FAMU to introduce students to strategies and habits that lead to college success through the improvement of their growth mindset, grit, and critical-thinking skills. Meeting twice a week, students gained an understanding of the importance of grit, and growth mindset, while developing critical-thinking skills. ISC1058 culminated with multiple workshops and seminars with expert outside speakers. First-year students who are transitioning from high school to university life can benefit from acquiring strategies for learning mastery, improving critical-thinking skills, and grit (Tables 1 and 3).

This study investigated how the ISC1058 course, developed around growth mindset, grit, and critical thinking influenced the academic success of first-year STEM majors. Our results suggested statistically significant improvements in student growth-mindset scores and GPA, as well as modest improvements in grit, and critical-thinking skills (Figure 2).

Applied life skills are as important as technical skills for college success and employability after graduation. In fact, Larson et al. [25] highlights the importance of continuously developing applied life skills and their link to student learning.

Student grit scores showed a moderate positive correlation with first-semester GPAs of STEM majors in the current study (Figure 3A). Similarly, Duckworth and Quinn [8] showed that higher grit scores may be linked to higher academic and personal achievement. Our study showed a moderate correlation between grit and performance. This is consistent with similar studies done at Iowa State University [26] and West Point Academy [9] were grit was shown to not be the most robust forecaster of student grades. Furthermore, this finding is of particular interest as prior researchers such as Crede et al. [13] and Muenks et al. [15] have stated similar findings that there may be alternative factors for prediction of academic performance.

Our data pointed to growth mindset as a success trait that favors academic achievement (Figure 3B). Indeed, previous research has shown that people who are successful in sports use growth-mindset 
strategies and push through setbacks without complaining [3]. In previous studies, while mindset was closely associated with academic performance [5], it was not a direct forecaster of academic success [26].

Second-semester GPAs of ISC1058 students were significantly improved compared to their first-semester GPAs. In this study, first-semester GPA showed a weak positive correlation with overall CAT scores (Figure 3C), and students with the highest CAT improvement from pre- to post-course performed better in the upper group (Table 2). Similarly, Stein et al. [17] observed a weak positive correlation between CAT and GPA $(\mathrm{r}=0.34)$.

Based on earlier research studies, it appears that incoming freshmen students could be taught to develop a growth mindset and subsequent improved academic performance $[4,27]$. There is a growing number of colleges that are increasingly focusing on undergraduate success. As an example, Cleveland State College infused growth mindset into their first-year seminar course and this intervention increased student growth mindset by as much as $20 \%$ [28].

\section{Conclusions}

The present study serves as a springboard for further focused work on promoting undergraduate student access. Taken together, our findings support the hypothesis that the college success course ISC1058: Scientist Life Skills designed for first-year STEM students at FAMU contributed to gains in a number of areas including growth mindset, GPA, and academic rank in course at the end of the semester. We have therefore developed a model scientist life skills course with clear benefits to growth mindset that can be adopted in non-STEM areas as well. Further research should explore specific mechanisms linking growth mindset and academic excellence. Finally, the new contributions of this study are summarized as followings: (a) There are not enough opportunities for students to gain STEM life skills; the new ISC1058 course described here can help students develop skills required for STEM success. (b) The study identified that teaching life skills leads to increases in growth mindset that raise student success and grade point averages. (c) This model life skills course can be adopted in non-STEM areas as well. (d) The findings of this study have implications not only for STEM majors at FAMU but also for other majors worldwide that need to implement scientist life skills such as growth mindset, grit, and critical thinking for higher student success.

Supplementary Materials: The following are available online at http://www.mdpi.com/2227-7102/10/10/279/s1, Table S1: ISC1058 Pacing Schedule.

Author Contributions: Conceptualization: G.H.; methodology: G.H., D.S., S.S., L.J., M.E.; validation, D.S., S.S. formal analysis: G.H., D.S., S.S.; resources: D.S., M.E.; data curation: G.H., D.S.; writing—original draft preparation: G.H.; writing—review and editing: G.H., D.S., S.S.; visualization, supervision: G.H., M.E., D.S.; project administration: M.E., D.S.; funding acquisition: M.E. All authors have read and agreed to the published version of the manuscript.

Funding: This research was funded by National Science Foundation (NSF, The United States of America) "Science Community of Active Learners to Enhance Achievement and Retention" Award no. 1719546.

Acknowledgments: We gratefully thank C. Akpovo for assistance in administering the CAT tests, and the Center for Assessment \& Improvement of Learning (Tennessee Tech University) for providing CAT institutional reports.

Conflicts of Interest: The authors declare no conflict of interest.

\section{References}

1. Deloitte and The Manufacturing Institute. Skills Gap and the Future of Work Study. 2018. Available online: https://documents.deloitte.com/insights/2018DeloitteSkillsGapFoWManufacturing (accessed on 15 September 2020).

2. Costa, A.; Kallick, B. Learning and Leading with Habits of Mind: 16 Essential Characteristics for Success; Association for Supervision and Curriculum Development: Alexandria, Egypt, 2008.

3. Dweck, C.S. Mindset: The New Psychology of Success; Random House Pub. Group: New York, NY, USA, 2006. 
4. Blackwell, L.S.; Trzesniewski, K.H.; Dweck, C.S. Implicit Theories of Intelligence Predict Achievement Across an Adolescent Transition: A Longitudinal Study and an Intervention. Child. Dev. 2007, 78, 246-263. [CrossRef]

5. Yeager, D.S.; Dweck, C.S. Mindsets That Promote Resilience: When Students Believe That Personal Characteristics Can Be Developed. Educ. Psychol. 2012, 47, 302-314. [CrossRef]

6. Yeager, D.S.; Hanselman, P.; Walton, G.M.; Murray, J.S.; Crosnoe, R.; Muller, C.; Tipton, E.; Schneider, B.; Hulleman, C.S.; Hinojosa, C.P.; et al. A national experiment reveals where a growth mindset improves achievement. Nature 2019, 573, 364-369. [CrossRef] [PubMed]

7. Duckworth, A.L. Grit: The Power of Passion and Perseverance; Scribner: New York, NY, USA, 2016.

8. Duckworth, A.L.; Quinn, P.D. Development and validation of the Short Grit Scale (Grit-S). J. Pers. Assess. 2009, 91, 166-174. [CrossRef] [PubMed]

9. Duckworth, A.L.; Quirk, A.; Gallop, R.; Hoyle, R.H.; Kelly, D.R.; Matthews, M.D. Cognitive and noncognitive predictors of success. Proc. Natl. Acad. Sci. USA 2019, 116, 23499-23504. [CrossRef] [PubMed]

10. Kelly, D.R.; Matthews, M.D.; Bartone, P.T. Grit and hardiness as predictors of performance among West Point cadets. Mil. Psychol. 2014, 26, 327-342. [CrossRef]

11. Lucas, G.M.; Gratch, J.; Cheng, L.; Marsella, S. When the going gets tough: Grit predicts costly perseverance. J. Res. Pers. 2014, 59, 15-22. [CrossRef]

12. Barshay, J. Research Scholars to Air Problems with Using 'Grit' at School. 2019. Available online: https: //hechingerreport.org (accessed on 15 September 2020).

13. Crede, M.; Tynan, M.; Harms, P.D. Much ado about grit: A meta-analytic synthesis of the grit literature. J. Personal. Soc. Psychol. 2017, 113, 492-511. [CrossRef] [PubMed]

14. Crede, M. What shall we do about grit? a critical review of what we know and what we don't know. Educ. Res. 2018, 47, 606-611. [CrossRef]

15. Muenks, K.; Yang, J.S.; Wigfield, A. Associations between grit, motivation, and achievement in high school students. Motiv. Sci. 2018, 4, 158-176. [CrossRef]

16. Paul, R.; Elder, L. The Miniature Guide to Critical Thinking Concepts and Tools; The Foundation for Critical Thinking Press: Dillon Beach, CA, USA, 2008.

17. Stein, B.S.; Haynes, A.F.; Redding, M.; Ennis, T.; Cecil, M. Assessing Critical Thinking in STEM and Beyond. In Innovations in E-learning, In-struction Technology, Assessment, and Engineering Education; Springer: Dordrecht, The Netherlands, 2017; pp. 79-82.

18. Han, C.; Farruggia, S.P.; Moss, T.P. Effects of Academic Mindsets on College Students' Achievement and Retention. J. Coll. Stud. Dev. 2017, 58, 1119-1134. [CrossRef]

19. Diehl, E. Classroom 2.0-Motivating Students with Mindset Coaching and How Brains Work (Dweck). 2008. Available online: http://www.classroom20.com/forum/topics/motivating-students-with (accessed on 15 September 2020).

20. Kannangara, C.S.; Allen, R.E.; Waugh, G.; Nahar, N.; Khan, S.Z.N.; Rogerson, S.; Carson, J. All that glitters is not grit: Three studies of grit in university students. Front. Psychol. 2018, 9, 1539. [CrossRef] [PubMed]

21. Babic, T.; Papic, S.; Babic, M. The importance of multiple intelligences and growth mindset—Research among students of University College Algebra. MIPRO 2018, 835-840. [CrossRef]

22. Kannangara, C.S.; Allen, R.; Carson, J.; Khan, S.; Waugh, G.; Kandadi, K. Onwards and upwards: The development, piloting and validation of a new measure of academic tenacity- the Bolton Uni-Stride Scale (BUSS). PLoS ONE 2020, 15, e0235157. [CrossRef] [PubMed]

23. Hacisalihoglu, G.; Stephens, D.; Johnson, L.; Edington, M. The use of active learning approach in a SCALE-UP learning space improves academic performance in undergraduate general biology. PLoS ONE 2018, 13, e0197916. [CrossRef] [PubMed]

24. Hacisalihoglu, G.; Hilgert, U.; Nash, E.B.; Micklos, D.A. An innovative plant genomics and gene annotation program for high school, community college, and university faculty. CBE—Life Sci. Educ. 2008, 7, 310-316. [CrossRef] [PubMed]

25. Larson, J.; Barnard, W.; Chandler, J.; O’Donnell, M.; Savenye, W.; Zapata, C.E. Moving Beyond Technical Skills: Fostering the Development of Essential Skills Needed for a Successful Career in Engineering. Geo Congr. 2020. [CrossRef]

26. Bazelais, P.; Lemay, D.J.; Doleck, T.; Hu, X.S.; Vu, A.; Yao, J. Grit, mindset, and academic performance: A study of pre-University science students. Eurasia J. Math. Sci. Technol. Educ. 2018, 14, em1615. 
27. Valentiner, D.P.; Mounts, N.S.; Durik, A.M.; Gier-Lonsway, S. Shyness entity mindset: Applying mindset theory to the domain of inhibited social behavior. Pers. Individ. Differ. 2011, 50, 1174-1179. [CrossRef]

28. Center for Community College Engagement. A Mind at Work: Maximizing the Relationship between Mindset and Student Success. 2019. Available online: https://www.ccsse.org/NR2019/Mindset.pdf (accessed on 15 September 2020). 